\title{
AUGUSTO DE CAMPOS TRADUTOR DE EMILY DICKINSON
}

\author{
Fernanda Maria Alves Lourenço* \\ Universidade Federal de Santa Catarina
}

\author{
Karine Simoni** \\ Universidade Federal de Santa Catarina
}

Silvia La Regina***

Universidade Federal do Sul da Bahia

\begin{abstract}
* Mestre em Estudos da Tradução (2014) pelo Programa de Pós-Graduação em Estudos da Tradução da Universidade Federal de Santa Catarina, com a dissertação “Tradução de poesia: Emily Dickinson segundo a perspectiva tradutória de Augusto de Campos”. É Bacharel em Secretariado Executivo Trilíngue pela Universidade Estadual de Maringá, com habilitação em Português/Inglês/Espanhol. Maringá, Paraná, Brasil. E-mail: feerfl@hotmail.com.

** Formou-se bacharel e licenciada em História (2000), mestre em História Cultural (2002), licenciada em Letras Italiano (2004), doutora em Letras (2009) e pós doutora em Estudos da Tradução pela Universidade Federal de Santa Catarina (2010). Professora do Departamento de Língua e Literatura Estrangeiras da Universidade Federal de Santa Catarina. Florianópolis, Santa Catarina, Brasil. E-mail: kasimoni@gmail.com.

**** Formou-se em Letras pela Università degli Studi di Roma La Sapienza (1990), mestre em Letras e Linguística pela Universidade Federal da Bahia - UFBA (1995), doutora em Letras e Linguística pela UFBA (2003), doutora em Lingue e Letterature Iberiche - Università degli Studi di Palermo (1999) e pós-doutora pela Università degli Studi di Roma La Sapienza (2008). Foi professora adjunta de Língua e Literatura Italianas na UFBA (2002-2008) e de Língua portuguesa, Literaturas portuguesa e brasileira e tradução da Università Gabriele d'Annunzio de Pescara (2009-2011). É Diretora da Rede de Centros de Idiomas da Universidade Federal do Sul da Bahia. Itabuna, Bahia, Brasil. E-mail: silvialaregina@gmail.com.
\end{abstract}


Resumo: Este artigo objetiva analisar a tradução de duas poesias de Emily Dickinson (1830-1886) realizada por Augusto de Campos (1931) e publicada em 2008 na coletânea Emily Dickinson: Não sou ninguém. Inicialmente serão apresentados alguns elementos da poética de Dickinson, a partir de Gilbert e Gubar (1984), Donoghue (1969), Sewall (1963) e Daghlian (1987). Em seguida, será dada ênfase à figura de Augusto de Campos como poeta e como tradutor, com destaque para os seus comentários sobre tradução, visando compreender sua prática tradutória (CAMPOS, 2004; 2006; 2008. Por fim, será analisada a tradução de duas poesias de Dickinson realizada por Augusto de Campos, buscando identificar a relação entre a teoria e a prática do tradutor. Essa análise, de caráter discursivo, além do plano formal e sintático, busca verificar o plano semântico dos textos, e ressalta que não tem a pretensão de realizar qualquer tipo de julgamento prescritivo.

Palavras-chave: Augusto de Campos. Tradução criativa. Poesia. Emily Dickinson.

\title{
AUGUSTO DE CAMPOS AS TRANSLATOR OF EMILY DICKINSON
}

\begin{abstract}
This article aims at analysing the translation of two poems by Emily Dickinson (1830-1886) carried out by Augusto de Campos (1931) and published in 2008 in the collected writings Emily Dickinson: Não sou ninguém ["Emily Dickinson: I'm nobody"]. Firstly, some elements of Dickinson's poetic shall be set forth, relying on Gilbert and Gubar (1984), Donoghue (1969), Sewall (1963), and Daghlian (1987). Afterwards, Augusto de Campos' figure as a poet and translator shall be highlighted, emphasizing his comments on translation as to understand his translation practice (Campos, 2004; 2006; 2008). Finally, Augusto de Campos' translation of two poems by Dickinson shall be analysed as to identify the relationship between translator's theory and practice. This rather discursive analysis, besides the syntactic and formal plan, endeavors to focus on the textual semantic layer, with no intentions to deploy any prescriptive judgments.
\end{abstract}

Keywords: Augusto de Campos. Creative translation. Poetry. Emily Dickinson. 
O tradutor, poeta e crítico brasileiro Augusto de Campos é reconhecido no âmbito nacional e internacional não apenas pelo seu singular fazer poético, mas também pelo seu fazer tradutório, conforme afirmam autores como Bassnett (2005), Paes (1990) e Barbosa \& Wyler (1998). No ensaio A tradução literária no Brasil, José Paulo Paes afirma que o trabalho de tradução de Augusto de Campos, assim como de seu irmão Haroldo, "teve efeito estimulante, incitando outros poetas a se dedicarem também às versões poéticas e abrindo um espaço para elas na imprensa literária" (PAES, 1990, p. 30-31). Da mesma forma, Barbosa e Wyler assinalam que "as reflexões teóricas dos irmãos Augusto de Campos e Haroldo de Campos a respeito de sua prática de tradução são o que há de mais próximo de uma teoria da tradução no Brasil" (1998, p. 332, tradução própria). Porém, apesar da crítica reconhecer a relevância dos irmãos Campos para os Estudos da Tradução, paradoxalmente, o contato de Augusto de Campos com a tradução ainda é pouco estudado no Brasil ${ }^{1}$. Vale lembrar que a sua produção como tradutor é maior do que a sua produção poética, conforme é possível averiguar em seu site pessoal < http://www2.uol.com.br/ augustodecampos/obras.htm $>$.

A relação de Augusto de Campos (doravante Campos) com a tradução teve início em conjunto com Haroldo de Campos e Décio Pignatari, membros do movimento concreto ${ }^{2}$, do qual também fazia parte. As traduções de Campos eram, em sua maioria, de autores pelos quais o movimento concretista tinha algum apreço, como Mallarmé, Maiakóvski, Ezra Pound e James Joyce. Destes, Pound parece ter inspirado Campos de maneira mais intensa e direta; tendo sido considerado por ele como "o modelo máximo do tradutor criativo moderno", pois "instituiu a crítica via tradução. Recriou a poesia do passado e elevou a tradução, muitas vezes, à categoria de suas próprias criações" (2004, p. 290, grifos nossos). Essa afirmação parece contemplar as características do modelo tradutório de Campos, intitulado por ele de "tradução-arte", isto é, uma tradução que não se limita ao literal, mas que busca manter a forma e o conteúdo artístico do texto de origem. Voltaremos a esse aspecto adiante. 
No conjunto de autores que integram os trabalhos de tradução de Campos, destacamos a poetisa norte-americana de considerável relevância no século XIX: Emily Dickinson (1830-1866). Para Campos, na poesia de Dickinson

\begin{abstract}
Cruzam-se os traços de um panteísmo espiritualizado, de uma solidão ora serena ora desesperada, e de uma visão abismal do universo e do ser humano. Micro e macrocosmo compactados em aforismos poéticos. Da observação da natureza, em suas mais humildes manifestações, ela consegue ascender às perguntas sem respostas da vida e da morte e do amor (ainda que recessivo e sublimado) em seus epigramasenigramas conceituais. Temas que percorreram a poesia de todos os tempos, mas assimilados aqui num idioleto de rara beleza. Sua geografia imaginária não tem limites (CAMPOS, 2007, p. 11).
\end{abstract}

Pautados na interpretação de Campos sobre Dickinson, pretendemos investigar se as concepções do tradutor sobre o ato tradutório são aplicadas nas traduções que ele fez da poetisa e, para tanto, analisaremos as traduções de dois poemas de Dickinson publicados em 2008, na obra Emily Dickinson: Não sou ninguém. Teremos como foco o plano semântico tanto das poesias de Dickinson quanto da tradução de Campos, e identificaremos casos como alterações, omissões, acréscimos e compensações, além de mencionarmos aspectos relativos à forma, especificamente à rima, à pontuação e ao uso das iniciais maiúsculas.

Este estudo é resultado de parte da dissertação de mestrado defendida em 2014 no Programa de Pós-graduação em Estudos da Tradução da Universidade Federal de Santa Catarina, e se justifica pelo fato de não se ter notícia, até o momento, de uma análise que trate, de forma sistemática, da tradução de Não sou ninguém, de Emily Dickinson, realizada por Campos. A fim de melhor alcançar o objetivo proposto, dividimos o estudo em dois momentos: 1) apresentação de alguns dos aspectos mais relevantes da vida e da 
poética de Dickinson e de Campos; e 2) análise e discussão dos poemas traduzidos.

\section{Emily Dickinson: elementos da poética}

Em uma das cartas enviadas ao crítico literário da revista Atlantic Monthly, Thomas W. Higginson, Dickinson discorre sobre a sua concepção de poesia. Afirma ela:

Se leio um livro e ele me gela o corpo de tal forma que nenhum fogo consegue me esquentar, sei que é poesia. Se sinto fisicamente como se a parte de cima da minha cabeça tivesse sido arrancada, sei que é poesia. Essas são as únicas maneiras que conheço (EMILY DICKINSON MUSEUM, 2009, p. 1).

Pode-se perceber nas palavras de Dickinson o quanto o labor poético significava para ela; este era uma espécie de companhia que a ajudava a expressar suas emoções, principalmente no período de reclusão, iniciado por volta de 1862. Daghlian comenta que, ao se isolar do mundo, Dickinson "queria um modo de vida que lhe permitisse representar o seu drama interior de renúncia” (1987, p. 194), que foi expresso por meio de textos em forma de poesia. Gilbert e Gubar (1984) consideram que o fato de Dickinson não ter escrito poemas narrativos ou textos em prosa é um dos aspectos que a diferencia de outras escritoras de sua época.

Como se sabe, o reconhecimento de Dickinson ocorreu efetivamente somente após a sua morte. Lira (2006) comenta que nenhum poeta e nenhuma poetisa do período recebeu tantas críticas negativas e incompreensões quanto ela, embora hoje seu trabalho seja amplamente reconhecido e valorizado. Os cerca de oito poemas de sua autoria que foram publicados em vida foram julgados negativamente por alguns críticos, o que teria causado em Dickinson uma grande aversão à publicação e à fama. Assim, a primeira publica- 
ção da obra de Dickinson, contendo 116 poemas, intitulada Poems by Emily Dickinson, foi realizada em 1890, quatro anos após a sua morte, por iniciativa de Thomas W. Higginson e de Mabel Loomis Todd. Ao todo, Dickinson escreveu aproximadamente 1775 poemas e 1049 cartas (cf. SEWALL, 1963).

Tanto os poemas publicados em vida quanto os publicados póstumos teriam sido modificados por Higginson e Todd, os quais "fizeram cortes e revisões para tornar mais regulares ritmos e rimas, e 'normalizar' a pontuação; dividiram as poesias por temas, e aplicaram-lhes títulos explicativos (que não existiam)" (ROMANELLI, 2003, p. 63), provavelmente para amenizar uma possível reação adversa do público. No entanto, as edições de Thomas $\mathrm{H}$. Johnson buscaram recuperar a autenticidade da poesia de Dickinson, e foram consideradas por críticos como Blackmur (1956), Donoghue (1969) e Campos (2007) como as mais fiéis ao manuscrito da poetisa, principalmente no que tange ao modo singular de Dickinson quanto à pontuação.

Dentre os temas tratados por Dickinson em suas poesias estão amores não correspondidos; dor e sofrimento; confronto entre a imaginação e a realidade (abstrato e concreto); percepção acerca da imortalidade; percepção de si própria; morte e religião. Vale destacar que o uso de travessões é constante na escrita de Dickinson e se constituiu quase como a única forma de pontuação, o que, na poesia do século XIX, representa uma inventividade na ruptura sintática (OBERHAUS, 1993). Para Campos o uso do travessão nas poesias de Emily Dickinson "lhe confere originalidade e extremo vigor poético" (2008a, p. 2) - provavelmente por esse motivo ao traduzir ele tenha se preocupado em manter tal característica da poetisa, como veremos a seguir. Dickinson também fazia uso de letras maiúsculas, geralmente em substantivos, como uma forma de dar destaque ao significado que a palavra assume dentro do poema. Outro elemento importante presente nas poesias de Dickinson são as rimas, que, segundo Small (2010), eram usadas na maioria das vezes como rimas perfeitas e, em seguida, alternadas para rimas imperfeitas, tipo este mais usado pela poetisa. 
Os poemas de Dickinson também se diferenciavam pela escolha de não seguir as regras gramaticais. Gomes, na introdução de Emily Dickinson: uma centena de poemas, assinala um dos fatores que pode ter influenciado a liberdade de criação presente na escrita dos poemas de Dickinson. Afirma ela:

Foi, provavelmente, na gramática poética de Shakespeare, que ela encontrou estímulo e encorajamento para a sua desarticulação de sintagmas costumeiros (processo frequente em sua poesia), cujo único critério de controle era o resultado final obtido, isto é, a nova ordem $(1984$, p. 27$)$.

No Brasil, a inserção de Dickinson teve início com o trabalho pioneiro de Manuel Bandeira, que, em 1928, publicou dois poemas traduzidos na revista Para Todos. Além de Bandeira, outros tradutores traduziram os poemas de Dickinson para a língua portuguesa, com destaque para Décio Pignatari, Cecília Meireles, Aíla de Oliveira Gomes, Carlos Daghlian, ${ }^{3}$ José Lira, bem como o tradutor que é nosso objeto de estudo - Augusto de Campos, do qual trataremos a seguir.

\section{Augusto de Campos: poesia e tradução}

Em suas entrevistas, Campos afirma que a prática de tradução é entendida como um modo de dialogar e, em parte, homenagear os autores que chamam a sua atenção e com os quais tem afinidade: "sempre fiz acompanhar as minhas traduções por considerações que envolvem traços caracterológicos dos autores no contexto do seu tempo e nunca deixei de me envolver emocionalmente com os poemas" (2008a, p. 3). Campos declara não ser um teórico da tradução (2008b, p. 276), mas podemos perceber que, no exercício da sua prática, estabelece uma reflexão e uma espécie de metodologia do traduzir, na qual "o conteúdo não deve ser pensado à letra, em 
unidades semânticas, mas como um conjunto formal-semântico-emocional, cujo espírito deve ser captado" (CAMPOS, 2008a, p. 1), o que significa que algumas pequenas "traições" possivelmente sejam feitas no processo de reconstrução do texto na cultura de chegada. Entretanto, essa não parece ser uma grande preocupação do tradutor, conforme afirma:

Não tendo a pretensão de acertar sempre, reivindico essa espécie de liberdade para as minhas interpretações tradutórias. A liberdade da improvisação e do rubato. Como se. Como se o poeta tivesse de expressar-se originariamente - resolver seu enigma fundo formal - na língua de chegada. Para aspirar à esperança de que o poema originário continue original em português (CAMPOS, 2007, p. 17).

Ao analisarmos o modus operandi de Campos no campo da tradução, é necessário considerar também os seus objetivos ao realizar a sua atividade tradutória. Além de divulgar o autor e o texto, no sentido de desvendá-los ao público para que sejam integrados nas "fontes de informação artística como nutrimento de impulso", a tradução serve também para "exercer uma forma de crítica, pois que a escolha e a análise textual implicam uma avaliação histórica e estética. Criar, sim, na medida em que a tradução-arte implica a cocriação ou re-criação de uma inflexão inexistente no idioma de chegada" (CAMPOS, 2004, p. 293).

Como se percebe, para Campos, a tradução é uma forma de crítica iluminadora, pois através dessa prática é possível realizar uma leitura e interpretação do texto fonte para recriá-lo (concisa e verbivocovisualmente) no texto traduzido, de maneira a conduzir o leitor para aquilo que considera ser primordial para o autor do texto de partida. Ou seja, como foi dito, Campos realiza as suas traduções a partir do que chama de "tradução-arte", entendido pelo seu irmão Haroldo como "transcriação". Seria como produzir um texto inédito na cultura de chegada, 
levando-se em conta tanto elementos linguísticos quanto estruturais e culturais.

Outro elemento importante para compreender o modo como Campos realiza as suas traduções é o conceito de antropofagia. A "antropofagia", ideia de devoração, é utilizada por Campos e se associa à ideia de canibalismo empregada por ele e por seu irmão Haroldo. Para Bassnett (2005), esse conceito pode ser aplicado a uma perspectiva alternativa sobre a tradução, na qual a imagem do tradutor se associa a um canibal devorando o texto original em um ritual que se converte na criação de algo novo. De acordo com Moreno, a antropofagia é um mecanismo fundamental utilizado pelos irmãos Campos, "pois, ao mesmo tempo em que ela sustenta, em termos teóricos, a deglutição de autores e textos que lhes interessam" (2001, p. 182), coloca tanto o projeto tradutório quanto o poético "na linha mais radical da vanguarda brasileira" (2001, p. 182). Ela surge como uma tentativa de "abrasileirar a nossa cultura, dando-lhe uma identidade" (MALTZ, 1993, p. 11), pois é por meio dela que os irmãos Campos (Augusto mais do que Haroldo) buscam instituir o objetivo do movimento concretista, ou seja, reformular a literatura brasileira (neste caso abrangendo também a tradução), a partir de uma "identidade estética” local. Em síntese, nas palavras de Haroldo de Campos, a Antropofagia

não envolve uma submissão (uma catequese), mas uma transculturação: melhor ainda uma 'transvaloração': uma visão crítica da história como função negativa (no sentido de Nietzsche), capaz tanto de uma de apropriação como de desapropriação, desierarquização, desconstrução (2006, p. 234).

Para Oswald de Andrade (1991), ser antropofágico significa prestar homenagem ao outro e não desmerecê-lo. A partir dessa afirmação, pode-se pensar a antropofagia praticada pelo tradutor-poeta Campos, no sentido de que este não realiza trabalhos tradutórios de qualquer autor, pelo contrário, busca selecionar com 
rigor as obras que irá traduzir, como uma forma de demonstrar admiração e prestígio para com tais obras e seus respectivos autores. Sobre o assunto, ressalta em uma entrevista: "As editoras nunca tiveram qualquer influência em meus trabalhos, jamais aceitei encomendas editoriais. Só traduzi e traduzo aquilo que amo, a poesia que me interessa e apaixona" (CAMPOS, 2012).

Após apresentarmos algumas das reflexões que norteiam o trabalho de Campos como tradutor, passaremos a analisar a tradução que realizou de duas poesias de Emily Dickinson, a fim de verificar a relação entre a teoria e a prática do tradutor.

\section{A tradução de Emily Dickinson: teoria e prática de Au- gusto de Campos}

Como foi dito, Campos ressalta que, ao escolher os autores dos quais deseja traduzir, tem a preocupação de divulgar no Brasil poetas que apresentam características inovadoras e pouco reconhecidas, fazendo com que críticos os considerem como intraduzíveis (CAMPOS, 2004, p. 286). Revela também que seu trabalho está na "desconstrução conceitual e reconstrução de sua leitura sob parâmetros não-canônicos” (2008a, p. 2), ou seja, sua intenção está na tentativa de desfazer preconceitos. No seleto grupo que Campos busca apresentar sob novos olhares, Emily Dickinson chamou a atenção do tradutor pelo fato da autora, além de não ter sido reconhecida por conta de sua produção poética pouco ligada ao que se produzia na época, ter sofrido preconceitos também pelo seu jeito discreto e isolado.

Para Campos, os textos da poetisa estão carregados de valores emocionais, respaldados por uma linguagem única e imprevisível, de modo a criar "um idioma poético próprio e antecipatório em termos de densidade léxica, economia de expressão e liberdade sintática" (CAMPOS, 2007, p. 10). Apesar de não expressar suas estratégias tradutórias na obra Emily Dickinson: não sou ninguém, o tradutor menciona como é desafiante "manter o clima emocional 
do texto [de Dickinson] permanecendo em sua área semântica" (CAMPOS, 2007, p. 13).

Partindo do pressuposto de que o modo de Campos traduzir encontra-se presente em suas traduções, analisaremos a seguir dois poemas de Dickinson por ele traduzidos, presentes na obra Emily Dickinson: Não sou ninguém, publicada em 2008. Para tanto, utilizaremos como suporte teórico Goldstein (2006) e Preminger e Brogan (1993).

A fim de melhor delimitar a análise, como foi dito, daremos foco ao plano semântico seja nas poesias de Dickinson, seja na tradução de Campos, e identificaremos casos como alterações, omissões, acréscimos e compensações. O objetivo do estudo não é o de realizar uma análise quantificativa, enumerando as ocorrências encontradas, tais como número de acréscimos, de omissões, dentre outras, mas, sim, discursiva, com a intenção de demonstrar as mudanças e correspondências entre os dois textos. Segundo Britto (2013), a grande maioria das análises poéticas são feitas no plano da forma e quase nada no plano semântico; portanto, no que diz respeito à forma, faremos expressivas menções quanto a aspectos como rima, pontuação e uso das iniciais maiúsculas.

Iniciamos a análise com a transcrição do poema $\mathrm{n}^{0} 1$.

1 Pain - has an Element of Blank -
2 It cannot recollect
3 When it begun - or if there were
4 A time when it was not -
1 It has no Future - but itself -
2 Its Infinite contain
3 Its Past - enlightened to perceive
4 New Periods - of Pain.

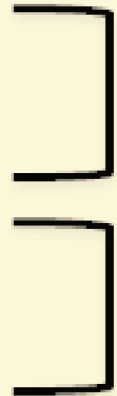

Escrito em 1862, esse poema, estruturado em duas estrofes de quatro versos, apresenta um tema bastante recorrente em Dickinson: a dor. Com estrutura simples, mas com denso conteúdo, o 
eu-lírico relata como classifica a dor, que, para a poeta, não se sabe quando tem início ou mesmo se há algum dia em que não esteja presente na vida de alguém. Ao caracterizar a dor como um elemento blank, de conotação "vazio", o leitor pode supor que, talvez, esse termo estivesse ligado à representação de Dickinson em ver e sentir a dor que nela habitava. Além disso, o eu-lírico assevera que não há futuro e nem passado da dor, já que ela simplesmente sempre existirá.

Em seguida a transcrição e a análise do original e da tradução da primeira estrofe.

\begin{tabular}{|l|l|}
\hline DICKINSON & CAMPOS \\
\hline $\mathbf{1}$ Pain - has an Element of Blank - & 1 A Dor - tem Algo de Vazio - \\
2 It cannot recollect & 2 Não sabe mais a Era \\
3 When it begun - or if there were & 3 Em que veio - ou se havia \\
$\mathbf{4}$ A time when it was not - & 4 Um tempo em que não era - \\
\hline
\end{tabular}

No primeiro verso, encontramos uma expressiva correspondência de Campos para a expressão Element of Blank [Elemento Vazio], traduzida por "Algo de Vazio", a qual parece indicar que o adjetivo blank, que também tem o significado de branco, foi vertido no poema para o sentido conotativo "vazio", provavelmente pelas demais relações presentes no texto. Além disso, outra escolha que chama a atenção e ocorre no verso sucessivo é com respeito à omissão de Campos do verbo recollect, que, de acordo com Oxford, significa "relembrar algo, fazer um esforço para re-

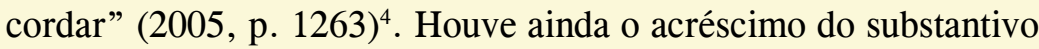
"Era", introduzido com maiúscula. Podemos julgar que o tradutor optou por esse acréscimo a fim de conseguir uma rima completa com o quarto verso.

Neste poema, notamos uma certa ousadia de Dickinson ao escrevê-lo. A poeta, do verso três para o quatro, apresenta um enjambement formado pela pausa entre there were (v. 3) e a time (v. 4). O que percebemos é que, ao juntarmos essa quebra, temos a 
frase there were a time [haviam(sic) um tempo], que sintaticamente não condiz com as normas do inglês padrão, pois o verbo to be [ser, estar], conjugado no passado simples, está se referindo ao plural were [eram, estavam] e, no entanto, seu complemento está no singular, já que temos a time - "um tempo" e o padrão seria There was a time. Essa inovação da sintaxe feita pela poetisa nos remete ao que ela escreveu certa vez para um colega: "você sabe como eu odeio ser comum"5 (SMALL, 2010, p. 29). Entretanto, apenas o efeito do enjambement foi mantido na tradução, a "anomalia sintática" não foi transposta para o português e nem teve algum correspondente, uma vez que Campos se ateve à concordância correta na língua portuguesa, optando por formular a frase no singular: "havia um tempo", talvez com a intenção de formar uma rima toante com a palavra "Vazio" do primeiro verso.

A anáfora, usada por Dickinson em versos seguidos, representa no poema uma repetição expressiva da estrutura; when [quando] aparece no terceiro e no quarto verso. Campos segue esse recurso e emprega a sua tradução para esse advérbio como "em que" duas vezes, no mesmo local em que o original. Destacamos a presença da aliteração, no original, da letra [w] (quatro vezes) e da letra [n] (oito vezes), totalizando doze recorrências e, no poema traduzido, somente da letra [e], mas que possui o mesmo número total do texto de Dickinson: doze vezes.

Quanto à questão das maiúsculas, no original temos três, enquanto no texto traduzido temos quatro. A pontuação, nessa estrofe, foi mantida em todos os aspectos por Campos, isto é, em número de ocorrências (3), no tipo (travessão) e no local que aparece no original. Em relação às rimas, vemos uma diferença notável entre original e tradução. Enquanto que o esquema rímico de Dickinson foi o mesmo do metro de balada - ABCB -, Campos optou por fazer um esquema de rimas - $\mathrm{ABAB}$. No original, temos a rima incompleta, rimando somente as consoantes finais, entre os versos 
pares (2 e 4) - recollect/not, e, na tradução, nos versos ímpares (1 e 3), a rima toante - vazio/havia.

Em relação à segunda estrofe, temos a seguinte análise:

\begin{tabular}{|l|l|}
\hline DICKINSON & CAMPOS \\
\hline $\mathbf{1}$ It has no Future - but itself - & $\mathbf{1}$ Seu Futuro é só Ela - \\
2 Its Infinite contain & 2 Seu Infinito faz supor \\
3 Its Past - enlightened to perceive & $\mathbf{3}$ O seu Passado - que desvela \\
$\mathbf{4}$ New Periods - of Pain. & $\mathbf{4}$ Novos Passos - de Dor. \\
\hline
\end{tabular}

Dickinson inova ao quebrar a sintaxe com o acréscimo da letra "s" nos verbos conjugados no presente nas pessoas "He/She/ It", conforme constatamos no segundo verso Its Infinite contain [Seu Infinito contém]. Nessa frase, seguindo a regra gramatical do inglês, o padrão seria o verbo to contain combinar com o sujeito Infinite, sendo conjugado como: contain[s]. Na tradução, além de não encontrarmos o mesmo efeito, também não notamos qualquer tipo de correspondente. No segundo verso, além de realizar um acréscimo, ao optar traduzir contain por dois verbos - "faz" e "supor", Campos se afasta do sentido do original, visto que o verbo to contain, segundo Oxford, quer dizer "ter alguma coisa dentro de outra ou fazer parte disso" $(2005, \text { p. 328 })^{6}$. Ou seja, no original, o verbo é usado como afirmação, o que dá a certeza do infinito que compõe o passado, uma relação mais metafórica, enquanto que, na tradução, há uma hipótese quanto à essa relação. Uma explicação para esse acréscimo esteja, talvez, no intuito do tradutor de formular uma rima com o último verso (supor/dor), mantendo assim o mesmo esquema do original, de rima completa nos versos pares.

No terceiro verso, Dickinson se utiliza de um vocabulário mais coloquial na expressão enlightened to perceive [iluminado/esclarecido para perceber], que foi transformado, por Campos, em "que desvela", expressão mais concisa e formal. A escolha do tradutor indica uma certa liberdade de sua parte, ao distanciar o sentido, pois o verbo "desvelar" na poesia comporta o sentido encontrado 
no dicionário Houaiss- "dar a conhecer, revelar" (2009, p. 673). Se fôssemos traduzir a expressão de modo literal, teríamos algo como "iluminado/esclarecido para perceber/notar". Mais uma vez, a escolha poderia ter a finalidade de produzir um esquema rímico entre "Ela" (v. 1) e "desvela" (v. 2).

Na pontuação, houve uma omissão do número de travessões presentes, de quatro no original para três no texto traduzido. Em relação ao uso de maiúsculas, ainda nesta estrofe, temos cinco letras maiúsculas no original, e, na tradução, além das mesmas cinco letras destacadas, encontramos uma maiúscula a mais, na palavra "Ela" do primeiro verso. Outra observação a ser feita é que, assim como na estrofe anterior, o uso do enjambement por Dickinson nos versos dois e três é mantido nos mesmos versos por Campos. Com relação ao esquema de rimas, Campos inovou com dois pares de rimas (CDCD), ao passo que, no poema de Dickinson, há somente um par (DEFE). Dito de outro modo, temos no original uma rima completa entre os versos pares (contain/pain); e na tradução temos uma rima completa, tanto entre os versos ímpares (ela/desvela) quanto entre os versos pares (supor/dor).

A seguir, analisaremos o poema $n^{0} 2$, com estrutura de três estrofes, e os habituais quatro versos em cada de Dickinson.

1 I died for Beauty - but was scarce 2 Adjusted in the Tomb

3 When One who died for Truth, was lain 4 In an adjoining Room -

1 He questioned softly "Why I failed"?

2 "For Beauty", I replied -

3 "And I-for Truth - Themself are One 4 We Brethren, are", He said -

1 And so, as Kinsmen, met a Night -

2 We talked between the Rooms -

3 Until the Moss had reached our lips4 And covered up - our names - 
Este poema, de acordo com o já referido site de Daghlian, foi o que mais recebeu traduções no Brasil, num total de vinte e uma. Dickinson o escreveu em 1862, e nele é contado um diálogo entre um homem e uma mulher à luz da temática da morte. Ambos estão em túmulos um ao lado do outro e, ao conversarem, descobrem que, apesar de o homem ter morrido pela verdade e a mulher pela beleza, eles são irmãos (Brethren), e tal conversa só termina quando seus lábios e nomes são cobertos pelo musgo/pela terra. Podemos considerar essa cena excêntrica e persuasiva como uma alusão à vontade platônica da poeta em desejar uma companhia, bem como ao fato de que todos os sentimentos, vontades e identidades humanas findarem-se com a morte. Partimos para a análise da primeira estrofe.

\begin{tabular}{|l|l|}
\hline DICKINSON & CAMPOS \\
\hline $\mathbf{1}$ I died for Beauty - but was & $\mathbf{1}$ Morri pela Beleza - e assim \\
scarce & que no Jazigo \\
$\mathbf{2}$ Adjusted in the Tomb & $\mathbf{2}$ Meu Corpo foi fechado, \\
$\mathbf{3}$ When One who died for & $\mathbf{3}$ Um outro Morto foi depositado \\
Truth, was lain & 4 Num Túmulo contíguo - \\
\hline
\end{tabular}

A palavra Tomb [tumba] (v. 2) é traduzida por uma de uso mais formal - "Jazigo" -, e foi reorganizada sintaticamente por Campos, que ao traduzir desloca o termo para o final do primeiro verso, enquanto no texto de Dickinson a palavra está no final do segundo verso. Para isso, ele omite o termo scarce [escasso/raro] do primeiro verso do original. A reorganização desse elemento poderia encontrar justificativa na relação que "Jazigo" faz com o acréscimo de "Meu Corpo", que aparece no início do verso seguinte, além de fazer parte do esquema rímico com a palavra "contíguo" (v. 4).

Ao final do verso dois, Campos produz uma pausa leve com a introdução de uma vírgula, que só é encontrada, no original, no terceiro verso, ao separar Truth [Verdade] de was lain [estava 
deitado]. Assim, encontramos uma liberdade de Campos que não parece ter causado mudança no significado do poema, já que este utiliza a vírgula para fazer uma pausa entre dois versos (v. 2 e v. 3), enquanto que Dickinson a utiliza para representar uma pausa entre dois elementos do mesmo verso (v. 3). Ainda nesse verso, temos o caso do verbo Adjusted [Ajustado] vertido para uma locução verbal "foi fechado".

Com relação ao uso do travessão, o poema traduzido segue e mantém tal recurso, havendo apenas a diferença quanto ao uso da vírgula, que foi antecipada na tradução, passando do terceiro para o segundo verso. Observamos uma mudança de classe gramatical no verso três, em que Dickinson apresenta o verbo died [morreu] precedido do pronome who [quem/que], expressão traduzida por Campos como "morto", que tem a função de substantivo masculino.

Além do mais, encontramos o sacrifício de alguns elementos mais explicativos, como o caso da palavra Truth [verdade]. Ela e Beauty [Beleza] são vocábulos repetidos ao longo das estrofes, e por isso podemos julgá-los relevantes para o contexto do poema, além de aparecerem em maiúscula, recurso de destaque bastante explorado por Dickinson e já comentado neste estudo. Por isso, acreditamos que, apesar de ter a característica da concisão presente em seus poemas e traduções, Campos, assim como repetiu a palavra "beleza", poderia manter também a repetição de "verdade". É importante sublinhar que, embora saibamos que a tradução mais livre é um dos recursos próprios de Campos, traduzir os dois termos em todas as estrofes é uma opção plausível, já que são elementos significativos e explicativos para o poema.

No esquema rímico, Campos não segue o mesmo de Dickinson, visto que esta utiliza o esquema do metro de balada, ABCB, enquanto o tradutor utiliza o esquema $\mathrm{ABBA}$, em que $\mathrm{B}$ são rimas emparelhadas e A rimas interpoladas, segundo o conceito de Goldstein (2006, p. 60). Em Dickinson, a rima dos versos pares (B) classifica-se como perfeita - tomb/room. Já em Campos, a rima entre o primeiro e o quarto verso (A) é toante - "Jazigo"/“Contíguo", enquanto que a rima entre o segundo e terceiro verso (B) é perfeita 
- "fechado"/ "depositado".

Passamos agora para a próxima estrofe.

\begin{tabular}{|l|l|}
\hline DICKINSON & CAMPOS \\
\hline $\mathbf{1}$ He questioned softly "Why I & $\mathbf{1}$ "Por que morreu?" murmurou \\
failed"? & sua voz. \\
$\mathbf{2}$ "For Beauty", I replied - & $\mathbf{2}$ "Pela Beleza" - retruquei - \\
$\mathbf{3}$ "And I - for Truth - Themself & $\mathbf{3}$ "Pois eu - pela Verdade - É o \\
are One - & Mesmo. Nós \\
$\mathbf{4}$ We Brethren, are", He said - & $\mathbf{4}$ Somos Irmãos. É uma só lei”. - \\
\hline
\end{tabular}

Logo no primeiro verso encontramos uma mudança feita por Campos, em que ele desloca a primeira pessoa do singular conjugada no original, na frase "Why I failed"? [Por que eu falhei?], para a terceira do singular, conforme podemos notar pela terminação do verbo conjugado "morrer" - "Por que morreu?". Além disso, o sujeito $\mathrm{He}$ [ele] é omitido, porém sua correspondência é conseguida pela versão "sua voz", que traz "voz" como uma informação adicional, pois não a encontramos no poema original. No segundo verso, Campos, ao invés de colocar uma vírgula após a palavra "Beleza", conforme consta no original, introduz um travessão, que compensa a falta que há no terceiro verso, já que, no poema original, temos três travessões e, na tradução, dois, pois um é substituído pelo ponto final, e, dessa forma, carrega uma pausa maior do que a imposta pelo travessão.

No terceiro verso, notamos uma anomalia linguística de Dickinson - a mudança de regra gramatical, com o uso desviante do pronome Themselves [eles mesmos], que no texto da poeta se encontra como Themself. Além disso, é possível observar outro efeito estilístico característico da poetisa no quarto verso, em que há uma quebra imposta por uma inversão sintática. A estrutura padrão do inglês SVO é apresentada nesse verso como SOV; exemplificando temos: "We Brethren, are" [Nós irmãos, somos]. Para o uso desviante do pronome não encontramos algo que se assemelhe ou se 
aproxime no texto traduzido, no entanto, há um correspondente para o segundo efeito estilístico de Dickinson. Campos compensa com um enjambement, e traz para o final do terceiro verso da tradução o sujeito da frase inicial do quarto verso do original, e assim temos um efeito semelhante, já que tal enjambement reproduz, parcialmente, o sentido de quebra imposto pela inversão sintática no original, resultando em - "Nós" (v. 3) / "Somos Irmãos" (v. 4).

$\mathrm{O}$ tradutor ainda opta por retirar o He said [Ele disse] (4v.) e introduzir "É uma só lei", dando ao verso um complemento que não existe no original, além de formar uma rima completa com "retruquei" $(2 \mathrm{v}$.). Outra marca de omissão pode ser vista no número e na posição dos travessões característicos de Dickinson. Ainda referente a esse verso, temos a palavra Brethren, de uso arcaico, que é um termo, de acordo com Vocabulary.com, bastante utilizado pela Bíblia para se referir a brothers [irmãos]. Ainda quanto ao seu significado, o Cambridge Dictionaries Online (< http://www. dictionary.cambridge.org/us $>$ ) a apresenta como um termo que é expresso em contextos religiosos. Portanto, nessa passagem, temos claro como a poesia de Dickinson, conforme Romanelli (2003) afirma, é ligada ao hino de igreja, e como a poeta fazia de suas origens puritanas uma das bases de seu pensamento.

Em sua versão, Campos faz uso da palavra "irmãos", que, além de possuir um registro mais coloquial, não indica totalmente o sentido imposto no original, já que não traz ao leitor qualquer referência a membros de uma religião. Uma opção seria traduzir Brethren por "irmãos na fé", que evidencia e se aproxima do sentido religioso.

Essa estrofe, como podemos observar, é marcada por diversos tipos de pontuação. No original, temos oito ocorrências, sendo uma com o ponto de interrogação, três com vírgula e cinco com o uso recorrente do travessão. Entretanto, na tradução esse número sobe para nove, e a disposição da pontuação não é totalmente mantida, além da vírgula ter sido trocada por ponto final.

O pronome $I$ [eu] é repetido, em versos sucessivos, três vezes no original. Podemos considerar a tentativa de Campos repetir as 
consoantes [p], as quais iniciam diferentes palavras nos três primeiros versos. No que tange às rimas, temos em Dickinson o esquema $\mathrm{CCDE}$, em que a rima entre o primeiro e o segundo verso $(\mathrm{C})$ pode ser classificada como incompleta - failed/replied, fazendo parte também dessa rima de consoantes a palavra said do verso quatro. No poema traduzido, o esquema rímico estabelecido é $\mathrm{CDCD}$, com rima toante entre os versos ímpares $(\mathrm{C})$ - voz/nós, e rima completa entre os versos pares (D) - retruquei/lei.

Por fim, analisaremos a terceira e última estrofe.

\begin{tabular}{|l|l|}
\hline DICKINSON & CAMPOS \\
\hline $\begin{array}{l}\text { 1 And so, as Kinsmen, met a } \\
\text { Night - }\end{array}$ & $\mathbf{1}$ E assim Parentes pela Noite, \\
$\mathbf{2}$ We talked between the & sábios - \\
Rooms - & Conversamos a Sós - \\
$\begin{array}{l}\text { 3 Until the Moss had reached } \\
\text { our lips - }\end{array}$ & $\begin{array}{l}\text { 3 Até que o Musgo encobriu } \\
\text { nossos lábios - }\end{array}$ \\
\hline
\end{tabular}

O termo no plural Kinsmen, de acordo com o dicionário Oxford (2005, p. 848), possui marca formal, significando parentes. Esse registro formal não se encontra na tradução, pois Campos opta por vertê-lo para "parentes", palavra que no português brasileiro possui uma marca mais coloquial. Por outro lado, o tradutor compensa as omissões já relatadas introduzindo novos termos. Um primeiro exemplo está no acréscimo do adjetivo "sábios" para classificar a palavra "parentes", criando com "lábios"(3v.), mais uma vez, uma rima do tipo perfeita.

Outro caso é percebido no verso dois, em que a expressão between the Rooms [entre os quartos] é traduzida por "a Sós”. Podemos supor que o fato de serem dois os personagens presentes no poema levou Campos a essa escolha, a qual se aproxima do sentido do original. No terceiro verso, é omitida a locução had reached [alcançou], e o verbo covered up, presente no quarto verso, é deslocado 
para o terceiro, por meio do qual faz a ligação do que ocorreu aos lábios e aos nomes com sua tradução literal - "encobriu". Além disso, talvez como uma forma de equilibrar tal omissão, Campos incorpora ao próximo verso a expressão "logo após”, que está subentendida, porém ausente, no original, de modo a formar uma rima entre "Sós" (3v.) e "após" (4v.). Contudo, tais escolhas tradutórias não fizeram com o que o sentido expresso pelo poema de Dickinson fosse perdido, além de ser possível notar termos traduzidos em seu sentido literal, tais como: We talked [Conversamos], Until the Moss [Até que o Musgo], our lips [nossos lábios], etc.

Em relação à rima, podemos notar uma diferença entre os dois textos. No poema original, temos FGHG, em que somente os versos pares (G) rimam e de maneira imperfeita com o som [ms] nas palavras - rooms/names. Todavia, no poema de Campos, temos EFEF, com rimas perfeitas tanto nos versos ímpares (E) - sábios/ lábios quanto nos pares $(\mathrm{F})$ - sós/após. Quanto ao recurso das maiúsculas, a tradução manteve todas as recorrências. Em relação à pontuação, encontramos no primeiro verso da tradução a omissão de uma das duas vírgulas do original, enquanto no quarto verso da tradução há o acréscimo de um travessão.

Nas análises realizadas, apesar de termos notado um notável número de versos traduzidos no sentido literal da palavra, tais observações nos mostram que há sim relação entre a teoria e a prática exercida por Campos, e que, na medida do possível, pode-se transpor o sentido do original para a tradução. Entendemos que algumas "perdas" sempre ocorrem na tradução, até porque, conforme Britto (2013), a poesia inglesa é cheia de detalhes sonoros e visuais, que muitas vezes não encontram o mesmo efeito no português.

Ao finalizar o estudo, utilizamos as palavras de Goldstein para apresentar o que encontramos no percurso de nossas análises do trabalho de Campos: "[...] em lugar da simetria, surge a irregularidade, o contraste, a dissonância, o efeito imprevisível ou inesperado" (2006, p. 50). Assim, neste trabalho, nos deparamos com a característica peculiar de Campos, ou seja, suas escolhas imprevisíveis e inusitadas, que resultam em cortes/omissões, 
acréscimos/liberdades tradutórias, criações e aproximações, e que fazem de Campos um importante nome da história presente da tradução no Brasil.

\section{Conclusão}

No exercício de análise da tradução de duas poesias de Emily Dickinson realizadas por Augusto de Campos, foi possível observar que, da mesma forma que o tradutor procurou recuperar o significado de algumas palavras em seu trabalho, ele expõe sua liberdade tradutória ao modificar passagens do original, omitindo e incorporando elementos inusitados. É o caso das palavras que se iniciam com letra maiúscula no meio dos versos, recurso usado por Dickinson para dar destaque a determinados termos dentro do poema. Na sua tradução, Campos omitiu algumas das palavras que na poesia de Dickinson iniciavam em maiúsculo, e por esse motivo o número de palavras em maiúsculo presente na tradução não alcançou o mesmo número de ocorrências do original.

Em relação ao número de versos, o tradutor conservou o mesmo indicador, bem como preservou a ausência de títulos nos poemas. Além disso, preocupou-se em manter algumas características da poesia de Dickinson, como o uso do travessão.

Tais constatações indicam que Campos utiliza na prática da tradução a ideia, defendida por ele, de que o significado deve ser levado em consideração; contudo, ao mesmo tempo, este deve ser interpretado não como uma unidade separada das demais partes do texto, mas como um conjunto de elementos, os quais, ao serem traduzidos, têm de produzir o impacto do original. Nesse processo, algumas "traições" serão necessárias e, por outro lado, haverá compensações.

Em relação à língua, Campos (2007) alega que Dickinson é uma poeta tendencialmente monossilábica, o que pode ser melhor compreendido diante da particularidade do inglês, que é uma língua basicamente mono e dissilábica, diferente do português, que 
possui em sua maioria palavras de três ou quatro sílabas (BRITTO, 2013). Porém, o que notamos na tradução são versos mais concisos e econômicos comparados ao original. Quanto a esse paradoxo, o tradutor reconhece essa característica do português, bem como do espanhol, italiano e francês que têm vocábulos "mais longos em confronto com o minissilabismo do inglês" (CAMPOS, 2004, p. 290). Embora haja essa diferença, mostramos que Campos é um poeta/tradutor que preza a concisão e a precisão, visto que a concisão do verso é maior na tradução. Em alguns casos, elementos importantes que fazem parte do sentido do poema foram cortados, porém, em suma, a carga semântica dos poemas buscou preservar as correspondências e o sentido da poesia de Dickinson.

Outra diferença entre as poesias está no registro linguístico utilizado. No original é possível notar que as poesias carregam um registro mais coloquial, embora ocorra casos de formalismos. Em Campos, encontramos vários trechos com um caráter mais formal que o texto de Dickinson, algumas podendo ser justificadas pelo intuito de formar rimas. Já as idiossincrasias de Dickinson, caracterizadas por Campos (2007) como uma liberdade linguística da poeta, foram traduzidas por estruturas do português padrão. Entretanto, não resultaram no afastamento do sentido do original, pelo contrário, a significação parece ter sido mantida. Além disso, percebemos que Dickinson apresenta casos de rimas mais imperfeitas, ao passo que Campos tende a rimas perfeitas. Em uma de suas entrevistas, Campos diz que, em uma tradução "se é rimado, vou rimar; se tem rimas ricas, vou fazer rimas ricas - tudo dentro daquele espírito de procurar reproduzir ao máximo os valores artísticos do original" (1995, p. 2). No texto do original, haviam rimas ricas, as quais tiveram suas equivalências para o português, confirmando a afirmação de Campos. Contudo, notamos que Campos parece constantemente sacrificar alguns elementos em função das rimas. Diante dessa constatação, é válido questionar: o excesso de rimas prejudicaria alguns resultados do tradutor? Onde se encontra o poeta da concisão nesses momentos? Conforme destacamos, Campos opta muitas vezes por acrescentar ou até mesmo omitir palavras para alcançar rimas. Ain- 
da que haja tais sacrifícios, se levarmos em conta a "tradução-arte" aplicada pelo tradutor, essas escolhas se encaixariam nas peculiaridades re-criativas do processo tradutório de Campos.

Por esses motivos, podemos considerar que, de um lado, tem-se o teórico criativo e inovador, de atividade tradutória peculiar, e, de outro, o tradutor que busca seguir o significado literal de muitos elementos do original, ao mesmo tempo em que recria outros, mas sempre aproximando a significação do poema em inglês para sua tradução na língua portuguesa do Brasil.

\section{Notas}

1. Ao realizarmos uma consulta junto ao banco de dados da CAPES, em 2014, constatamos que foram feitas vinte e oito pesquisas a seu respeito, entre dissertações e teses, e destas somente cinco tratam de tradução, o que justifica a realização de mais estudos acerca de Augusto de Campos como tradutor.

2. O propósito desse movimento era apresentar novos parâmetros para a produção de poesia no Brasil, abolindo a forma usual do verso e substituindo-a por uma "estrutura gráfico-espacial, ideogrâmica". (CAMPOS, Augusto, 2006, p. 71) O poeta concreto, segundo o manifesto escrito por Augusto e publicado pela primeira vez em 1956, "vai direto ao seu centro, para viver e vivificar a sua facticidade. [...] Vê a palavra em si mesma - campo magnético de possibilidades - como um objeto dinâmico, uma célula viva, um organismo completo". (2006, p. 71)

3. No site <http://www.ibilce.unesp.br/\#388,414>, organizado por Carlos Daghlian, há um vasto conjunto de livros, periódicos, trabalhos acadêmicos, traduções, divulgação de eventos, entre outras informações ligadas à poetisa, no Brasil e em Portugal.

4. To remember sth, especially by making an effort to remember it. 
5. [...] you know how I hate to be commom.

6. [...] it has that thing inside it or as part of it [...].

\section{Referências}

ANDRADE, Oswald de. Obras completas. São Paulo: Globo, 1991.

Cambridge Dictionaries Online. Disponível em: http://www.dictionary.cambridge.org/us. Acesso em 2 ago 2013.

CAMPOS, Augusto de. Entrevista sobre a tradução de "Não sou ninguém" [mensagem pessoal]. Mensagem recebida por < kasimoni@gmail.com>; < feerfl@ hotmail.com > em 02 setembro 2012.

. Poesia concreta (manifesto). In: CAMPOS, Augusto de; PIGNATARI, Décio; CAMPOS, Haroldo de. Teoria da Poesia Concreta: textos críticos e manifestos 1950 - 1960. Cotia: Ateliê Editorial, 2006. p. 71 - 76.

. Augusto de Campos: em busca da "alma" e da "forma". Revista do Instituto Humanitas Unisinos, São Leopoldo, n. 276, ano VIII, 6 out. 2008a. Entrevista concedida à André Dick. Disponível em: < http://www.ihuonline.unisinos. $\mathrm{br} /$ index .php? option $=$ com content $\&$ view $=$ article $\&$ id $=2212 \&$ secao $=276>$. Acesso em: 26 out. 2014.

. Entrevista a João Queirós. In: Cadernos de Tradução. v. 2, n. 22. Florianópolis: UFSC/PGET, $2008 \mathrm{~b}$.

. Introdução. 2007. In: Dickinson, Emily. Emily Dickinson: Não sou ninguém. Trad. Augusto de Campos. Campinas: Editora UNICAMP, 2008. p. 09 - 17. 
.Entrevista concedida por Augusto de Campos à Inês Oseki-Dépré. In: SÜSSEKIND, Flora; GUIMARÃES, Júlio Castañon. Sobre Augusto de Campos. Rio de Janeiro: 7Letras, 2004.

. Augusto de Campos. Disponível em: < http://www2.uol.com.br/augustodecampos/obras.htm >. Acesso em: 26 out. 2014.

CAMPOS, Haroldo de. Metalinguagem \& outras metas: ensaios de teoria e crítica literária. São Paulo: Perspectiva, 2006.

BARBOSA, Heloísa Gonçalves; WYLER, Lia. Brazilian tradition. In: BAKER, M. (Dir.). Routledge encyclopedia of translation studies. London/ New York: Routledge, 1998. p. 326-332.

BASSNETT, Susan. Estudos de Tradução. Trad. Sônia Terezinha Gehring et al.. Porto Alegre: Editora da UFRGS, 2005.BLACKMUR, R. P. Emily Dickinson's Notation. 1956. In: SEWALL, Richard Benson. Emily Dickinson. A Collection of Critical Essays. New York, Prentice-Hall, Inc., Englewood Cliffs, 1963. p. 78-87.

BRITTO. Paulo Henriques. O que é poesia? Casa das rosas. São Paulo, abril 2013. Disponível em: <https://www.youtube.com/watch?v=-yHyrLxEtAI > Acesso em: 26 out 2014.

DAGHLIAN, Carlos. A obsessão irônica na poesia de Emily Dickinson. 1987. 310f. Livre Docência - Universidade Estadual de São Paulo, São José do Rio Preto, 1987.

DONOGHUE, Denis. Emily Dickinson. 81. ed. Minneapolis: University of Minnesota, 1969.

EMILY DICKINSON MUSEUM. 2009. Disponível em: < http://www.emilydickinsonmuseum.org > . Acesso em: 26 out. 2014.

GILBERT, Sandra M; GUBAR, Susan. The madwoman in the attic: the woman writer and the nineteenth-century literary imagination. New Haven: Yale University Press, 1984. 
GOLDSTEIN, Norma Seltzer. Versos, sons, ritmos. São Paulo: Ática, 2006.

GOMES, Aíla de Oliveira. Introdução. In: DICKINSON, Emily. Emily Dickinson: uma centena de poemas. Trad. Aíla de Oliveira Gomes. São Paulo: Edusp, 1984.

HOUAISS, Antonio. Novo dicionário Houaiss da Língua Portuguesa. Rio de Janeiro: Objetiva, 2009.

LIRA, José. Emily Dickinson e a poética da estrangeirização. In: PG Letras 30 anos - O Caminho se Faz Caminhando, 2006, Recife. Anais eletrônicos. Recife: 2006, UFPE, PPGEL. v. 1, n. 1, p. 556 - 569. Disponível em: < http://www. pgletras.com.br/Anais-30- Anos/Docs/Artigos/5. \%20Melhores \%20teses \% 20 e\%20dissertações/5.5_Jose_Lyra.pdf > . Acesso em: 2 ago 2013.

MALTZ, Bina. Antropofagia: rito, metáfora e pau-brasil. In: MALTZ, Bina; TEIXEIRA, Jerônimo; FERREIRA, Sérgio. Antropofagia e Tropicalismo. Porto Alegre: UFRGS, 1993.

MORENO, Silene. Ecos e reflexos: a construção do cânone de Augusto e Haroldo de Campos a partir de suas concepções de tradução. Tese (Doutorado em Linguística Aplicada) - Instituto de Estudos da Linguagem, Universidade Estadual de Campinas. 2001.

OBERHAUS, Dorothy Huff. Emily Dickinson's Book. The Emily Dickinson Journal, v. 2, n. 2, p. 58-65. 1993.

OXFORD. Advanced Learners's Dictionary. $7^{\text {th }}$ edition. Oxford: Oxford University Press, 2005.

PAES, José Paulo. A tradução literária no Brasil. In: Tradução: a ponte necessária. Aspectos e problemas da arte de traduzir. São Paulo: Ática, 1990.

PREMINGER, Alex; BROGAN, T. V. F. The new Princeton encyclopedia of poetry and poetics. Princeton New Jersey: Princeton University Press, 1993. 
ROMANELLI, Sérgio. De poeta à poeta: a única tradução possível? O caso Dickinson/Virgillito. Uma análise descritiva. 2003. 153 f. Dissertação (Mestrado em Letras e Linguística) - Universidade Federal da Bahia, Salvador.

SEWALL, Richard Benson. Emily Dickinson. A Collection of Critical Essays. New York, Prentice-Hall, Inc., Englewood Cliffs, 1963.

SMALL, Judy Jo. Positive as sound: Emily Dickinson's rhyme. Athens, Georgia: University of Georgia Press, 2010.

Recebido em: 08/06/2015

Aceito em: 03/08/2015 